\title{
TU/e EN⿴HONE

\section{Fast fourier transform based diagnostics for spectral characterization of millimeter waves in tokamaks}

\section{Citation for published version (APA):}

Thoen, D. J., Bongers, W. A., Westerhof, E., Oosterbeek, J. W., Baar, de, M. R., Berg, van den, M. A., Beveren, van, V., Bürger, A., Goede, A. P. H., Graswinckel, M. F., Hennen, M. F., \& Schüller, F. C. (2009). Fast fourier transform based diagnostics for spectral characterization of millimeter waves in tokamaks. In 34th International Conference on Infrared, Millimeter, and Terahertz Waves, IRMMW-THz 2009, 21 September - 25 September 2009, Busan (pp. 5325586-1/2). Institute of Electrical and Electronics Engineers. https://doi.org/10.1109/ICIMW.2009.5325586

DOI:

10.1109/ICIMW.2009.5325586

Document status and date:

Published: 01/01/2009

\section{Document Version:}

Publisher's PDF, also known as Version of Record (includes final page, issue and volume numbers)

\section{Please check the document version of this publication:}

- A submitted manuscript is the version of the article upon submission and before peer-review. There can be important differences between the submitted version and the official published version of record. People interested in the research are advised to contact the author for the final version of the publication, or visit the $\mathrm{DOI}$ to the publisher's website.

- The final author version and the galley proof are versions of the publication after peer review.

- The final published version features the final layout of the paper including the volume, issue and page numbers.

Link to publication

\section{General rights}

Copyright and moral rights for the publications made accessible in the public portal are retained by the authors and/or other copyright owners and it is a condition of accessing publications that users recognise and abide by the legal requirements associated with these rights.

- Users may download and print one copy of any publication from the public portal for the purpose of private study or research.

- You may not further distribute the material or use it for any profit-making activity or commercial gain

- You may freely distribute the URL identifying the publication in the public portal.

If the publication is distributed under the terms of Article 25fa of the Dutch Copyright Act, indicated by the "Taverne" license above, please follow below link for the End User Agreement:

www.tue.nl/taverne

Take down policy

If you believe that this document breaches copyright please contact us at:

openaccess@tue.nl

providing details and we will investigate your claim. 


\title{
Fast Fourier Transform based Diagnostics for Spectral Characterization of Millimeter Waves in Tokamaks
}

\author{
D.J. Thoen ${ }^{\mathrm{a}}$, W.A. Bongers ${ }^{\mathrm{a}}$, E. Westerhof ${ }^{\mathrm{a}}$, J.W. Oosterbeek ${ }^{\mathrm{b}}$, M.R. de Baar ${ }^{\mathrm{a}}$, M.A. van den Berg ${ }^{\mathrm{a}}$, \\ V. van Beveren ${ }^{a}$, A. Bürger ${ }^{b}$, A.P.H. Goede ${ }^{a}$, M.F. Graswinckel ${ }^{\mathrm{a}}$, M.F. Hennen ${ }^{\mathrm{a}, \mathrm{c}}$, F.C. Schüller ${ }^{\mathrm{a}}$ \\ and the TEXTOR-team ${ }^{\mathrm{b}}$
}

${ }^{a}$ FOM-Institute for Plasma Physics Rijnhuizen, Partner in the Trilateral Euregio Cluster P.O. Box 1207, 3430 BE Nieuwegein, The Netherlands, www.rijnhuizen.nl

${ }^{\mathrm{b}}$ Forschungszentrum Jülich GMBH, Institut für Energieforschung - Plasmaphysik, Association EURATOM-FZJ, 52425 Jülich, Germany, www.fz-juelich.de

${ }^{c}$ Eindhoven University of Technology, Control Systems Technology Group, PO Box 513, NL-5600 MB Eindhoven, The Netherlands

\begin{abstract}
A Fast Fourier Transform (FFT) based wide range millimeter wave diagnostics for spectral characterization of scattered millimeter waves in plasmas has been successfully brought into operation. The scattered millimeter waves are heterodyne down-converted and directly digitized using a fast analog-digital converter (ADC) and a compact Peripheral Component Interconnect (cPCI) computer. Frequency spectra are obtained by FFT in the time domain of the intermediate frequency signal. The scattered millimeter waves are generated during high power Electron Cyclotron Resonance Heating (ECRH) experiments on the TEXTOR Tokamak and demonstrate the performance of the diagnostics and, in particular, the usability of direct digitizing and Fourier transformation of millimeter wave signals. Major benefit of the new diagnostics is a tunable time and frequency resolution due to post-detection, near-Real-Time processing of the acquired data. This diagnostics has a wider application in astrophysics, earth observation, plasma physics and molecular spectroscopy for the detection and analysis of millimeter wave radiation, providing high-resolution spectra at high temporal resolution and large dynamic range. Such a diagnostics also has the potential to detect Electron Cyclotron Emission (ECE) and to be used in Real-Time ECE feedback control systems.
\end{abstract}

\section{INTRODUCTION AND BACKGROUND}

I $\mathrm{n}$ a Tokamak, which is the main route to fusion power $\mathbf{I}_{\text {plants, high temperature plasma is confined by magnetic }}$ fields, which form closed toroidal magnetic surfaces [1]. Fusion performance limiting instabilities can occur in these plasmas with for example the Neoclassical Tearing Mode (NTM). NTMs lead to a local loss of current in the islands.

The suppression of NTMs by high power Electron Cyclotron Waves (ECW) has been demonstrated on a number of Tokamaks. Absorption of these waves as well as Electron Cyclotron Emission (ECE) occurs in the region where the wave frequency is resonant with the electron cyclotron frequency or one of its harmonics. In Tokamaks, the relevant frequencies are of the order of $100 \mathrm{GHz}$. Suppression of NTMs is achieved by replacing the missing current inside the island by currents driven by the ECW power. Effective and efficient control of NTMs therefore requires accurate localization.

The TEXTOR Electron Cyclotron Resonance Heating (ECRH) installation [2] consists of a $140 \mathrm{GHz}, 800 \mathrm{~kW}, 10 \mathrm{~s}$ gyrotron with steerable launcher. The installation features a pilot scheme of a line-of- sight feedback system [3] (In-Line), designed to detect the radial location of the island and the phase between O-point and X-point. In this scheme the ECW launcher is used as antenna to feed an ECE spectrum centered on the gyrotron frequency through the ECW transmission line into a radiometer.

During In-Line ECE measurements an unexpectedly strong millimeter wave signal was observed, limiting operation of the In-Line receiver. The nature of this spurious signal is yet unknown and is new physics [4]. By its frequency content it is shown to be no direct reflection of the ECH\&CD waves from the plasma. Investigation of the origin of the spurious signals requires measurements at high frequency resolution, high temporal resolution and high dynamic range. Therefore a new dedicated diagnostics has been developed [5], using direct digitizing and post data acquisition, near-Real-Time (RT) processing based on Fast Fourier Transform (FFT).

\section{SET-UP}

The basic set-up of the diagnostics is a heterodyne frontend down converting the Radio Frequency (RF) band of interest (136-140 GHz) to the lower Intermediate Frequency (IF) band (DC-4 GHz). The signal is amplified by an amplifier (Noise Figure (NF) $=4.6 \mathrm{~dB}$, Gain $34 \mathrm{~dB}$ ) and filtered with an anti-aliasing filter on-board the analog to digital converter (ADC). The broadband IF signal is directly digitized with the high speed ADC and near-RT processed with Fast Fourier Transform (FFT) algorithms for frequency spectra. To retrieve a spectrogram with a range of $4 \mathrm{GHz}$, Nyquist states that a sampling rate of at least $8 \mathrm{GHz}$ is required. Extensive research on the optimal component selection has been carried out, 
dominated by digitizer performance. The ADC of choice is an Agilent Technologies/Acqiris DC222 ADC, in combination with a compact Peripheral Component Interconnect (cPCI) dual core computer for near-RT signal processing. The ADC is operated and the signals are processed by LabVIEW $^{\circledR}$. Measurements are initiated by a predefined number of external hardware triggers, corresponding to the waveforms to be converted to frequency spectra.

\section{THEORY}

In a FFT the frequency resolution $\Delta f$ is determined by: $\Delta f=f_{s} / N$, with $f_{s}$ the sampling frequency of the ADC and $N$ the time domain number of samples in the waveform (series of acquired samples). For a fixed sample rate, the frequency resolution, dynamic range and waveform rate are dependent on the time domain sample size [5], resulting in a tunable frequency resolution and allowing for optimization of the time and frequency resolution. The least detectable power of an FFT based radiometer can be calculated with $P_{\min }=k_{B} f_{s} T_{\text {total }} \sqrt{1 / N}$, where $k_{B}$ is Boltzmann's constant and $T_{\text {total }}$ the total equivalent noise temperature in Kelvin. The calculated equivalent noise temperature of this FFT radiometer is $3.5 \times 10^{4} \mathrm{~K}$, giving a $T_{\text {total }}=18 \times 10^{6} \mathrm{~K}$.

\section{RESULTS}

Low power system tests showed compliance with the requirements [5]. The diagnostics is able to acquire $4 \mathrm{GHz}$ wide spectra of signals in the range $136-140 \mathrm{GHz}$. The rate of spectra is tunable and has been tested between $200 \mathrm{k}$ spectra/s for a frequency resolution of $100 \mathrm{MHz}$, via $10 \mathrm{k}$ spectra/s $(1.0 \mathrm{MHz}$ frequency resolution) and $120 \mathrm{spectra} / \mathrm{s}$ with a frequency resolution of $25 \mathrm{kHz}$. The respective dynamic ranges are 63,86 and $103 \mathrm{~dB}$. This allows for $\sim 1 \mathrm{~s}$ record length, limited by the 2 GB RAM memory of the computer.

Validation and measurements on TEXTOR during high power ECRH pulses show the diagnostic is capable of detecting scattered signals [4]. In figure 1 time resolved frequency spectra of mm-wave radiation are shown. The dynamic ergodic divertor (DED) on TEXTOR is used to excite $\mathrm{m} / \mathrm{n}=2 / 1$ tearing modes in the plasma. The island is rotating at a frequency of 2 $\mathrm{Hz}$, and moved with the DED through the observation region of the In-Line ECE system. The scattering is in phase with the island rotation [4]. The dark blue spacing from $50 \mathrm{~ms}$ to $280 \mathrm{~ms}$ is showing the calibrated noise floor as well as reflected gyrotron signals. The yellow line in this time interval is the gyrotron frequency, being suppressed over $120 \mathrm{~dB}$. The green line is a harmonic of the gyrotron.

\section{DISCUSSION AND FUTURE WORK}

An FFT millimeter wave diagnostics for high frequency resolution and high temporal resolution research has been developed. A heterodyne front-end is combined with an $8 \mathrm{GHz}$ high speed $\mathrm{ADC}$ from Acqiris/Agilent Technologies.
Validation tests show that the performance of the diagnostic matches or exceeds the requirements that were defined.
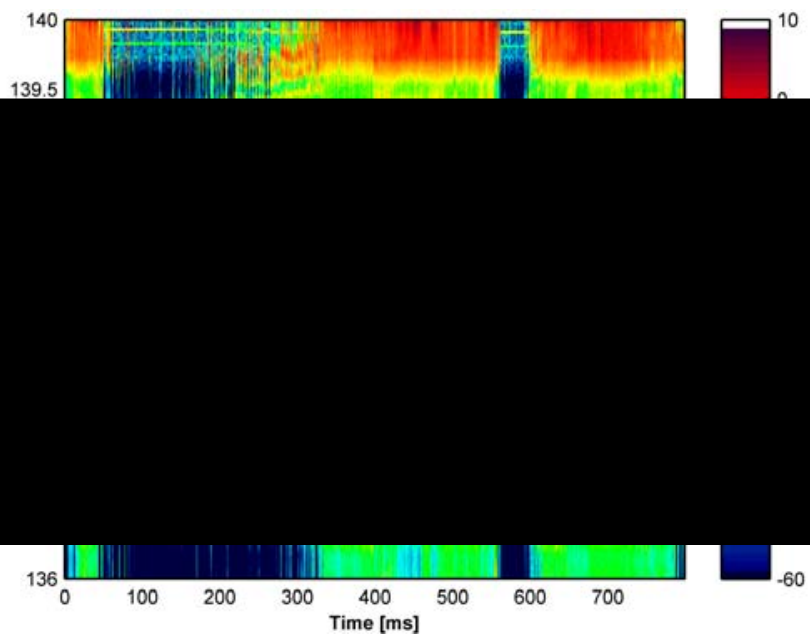

Figure 1 Plot of time-resolved frequency spectra of mm-wave radiation in the TEXTOR Tokamak, shot number 108086. The DED is used to move the magnetic island slightly back-and-fourth through the observation region with a frequency of about $2 \mathrm{~Hz}$. The thin yellow/green lines in the $139.8 \mathrm{GHz}$ range are the reflections on the plasma of the gyrotron and one of its harmonics. The gyrotron signals are being suppressed more than $120 \mathrm{~dB}$. The frequency resolution is $0.2 \mathrm{MHz}$ with a time resolution of $1 \mathrm{~ms}$. The dynamic range of signal power exceeds $60 \mathrm{~dB}$.

Future work on improved FFT millimeter wave diagnostics includes:

- Use of a $140 \mathrm{GHz}$ phase locked oscillator to decrease local oscillator noise in the IF components;

- Optimizing the SNR by replacing the current mixer (Conversion loss $\sim 15 \mathrm{~dB}$ ) and amplifier for low noise, broadband components $\left(\mathrm{NF}_{\text {mixer }} \sim 5 \mathrm{~dB}, \mathrm{NF}_{\text {amp }} \sim 1 \mathrm{~dB}\right)$ in order to be able to detect ECE;

- Optimizing software, memory and (multi core) processor settings for both increasing the amount of data stored and to explore the possibility of RT $(10 \mathrm{kHz})$ data processing;

- Combination with the In-Line ECE system on ASDEX-U [6] could result in an ECE feedback system with tunable spatial resolution.

\section{REFERENCES}

[1] J. Wesson, Tokamaks, Oxford University Press, USA, 2004.

[2] E. Westerhof, et al., "Tearing mode stabilization by electron cyclotron resonance heating demonstrated in the TEXTOR tokamak and the implication for ITER," Nuclear Fusion, vol. 47, 2007, pp. 85-90.

[3] J.W. Oosterbeek, et al., "A line-of-sight electron cyclotron emission receiver for electron cyclotron resonance heating feedback control of tearing modes," Review of Scientific Instruments, vol. 79, 2008, pp. 093503-12.

[4] E. Westerhof, et al., "Strong scattering of high power mm-waves in tokamak plasmas with tearing modes," Accepted for publication Phys.Rev.Letters.

[5] D.J. Thoen, W.A. Bongers, et al., "Development and Testing of a Fast Fourier Transform High Dynamic Range Spectral Diagnostics for Millimeter Wave Characterization," Submitted for publication Review of Scientific Instruments.

[6] W.A. Bongers et al., "ECE System on ASDEX-Upgrade placed Inline at the high power waveguide based transmission system," This conference, Busan: 2009. 